\title{
Supply and Demand: Government Interference with the Unhampered Market in U.S. Health Care
}

\author{
Gilbert Berdine $M D$
}

Many of the terms and concepts used by economists are poorly understood by the general public. This article will try to explain basic terms and concepts of economics and illustrate how they apply to U.S. Health Care. None of the material presented is controversial or dependent on the school of economic thought to which one belongs.

Figure 1.

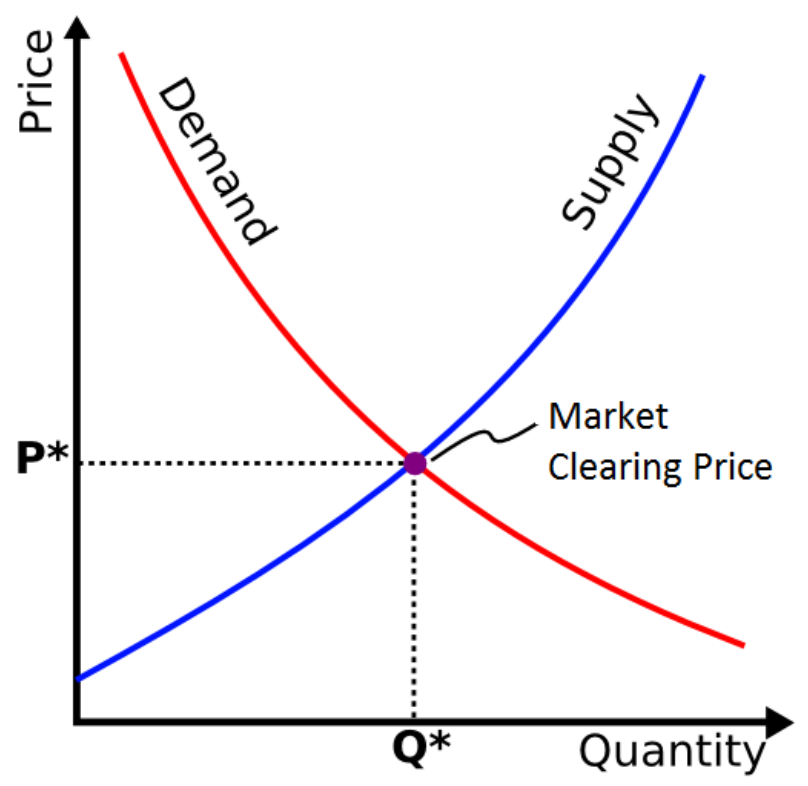

Figure 1 is a basic illustration of supply and demand in what is called the unhampered or free market. The free market is quite simple: a free market exists wherever and whenever two or more people

Corresponding author: Gilbert Berdine MD Contact Information: Gilbert.Berdine@ttuhsc.edu DOI: $10.12746 /$ swrccc 2014.0207.085 get together to voluntarily exchange goods. There are no regulations as to what can be sold, what can be purchased or what prices can be charged. The only restriction is that all exchanges are voluntary rather than coerced by force.

Contrary to popular thinking, neither supply nor demand is a single number. Rather, both supply and demand are a family of numbers representing the price at which a quantity of goods will be either sold (supply) or purchased (demand). The shapes of the two curves depend on many things, but there are a few generalizations that can be made. The slope of the supply curve must everywhere be greater than or equal to zero. One cannot possibly induce (in a free market) a greater supply by offering a lower price. The slope of the demand curve must everywhere be less than or equal to zero. One cannot possibly get more people to purchase a given good by asking for a greater price.

Given the constraints on slope, the supply and demand curve must always intersect at a point. That point is called the market clearing price. This is the price at which all people in the market will be left satisfied. This is not to say that everyone will make a purchase or sale. All the people who sell will value the market clearing price greater than the good sold. All the people who buy will value the good purchased greater than the market clearing price. All the people who do not sell the good value the good greater than the market clearing price - just like those who purchased the good. All the people who do not buy the good value the market clearing price more than the good - just like those who sold the good. At the end of the day, everyone is left with what they value more - either the good or the market clearing price amount of money. There are no unsatisfied sellers or buyers. 
The only way to change the number of exchanges would be for either the buyers or sellers to change their priorities.

One type of government interference with the unhampered or free market is regulation. A regulation decreases the number of people who can or will legally sell at a given price. For each price the quantity available for supply is decreased.

Figure 2.

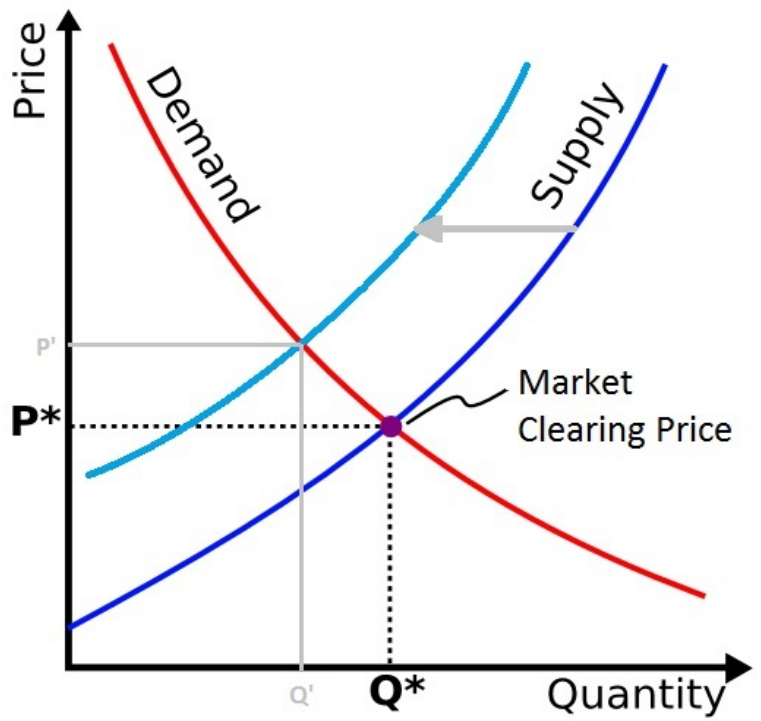

As Figure 2 illustrates, the supply curve has been shifted to the left. There are two effects-one is intended and the other is unintended. The purpose of the regulation was to decrease the number of exchanges. The regulation might require the seller to be licensed. The regulation might require the good or packaging to meet certain standards. The regulation might limit the time of day or the day of the week that the transaction can occur. The intended consequence of all regulations is to eliminate unwanted (by the government) transactions. The regulation is successful in this regard as the new market clearing quantity (Q') is less than the unhampered market clearing quantity $\left(Q^{*}\right)$. As we can see from Figure 2, the unintended consequence of the regulation is to raise the market clearing price. The U.S. Health Care system is full of regulations whose stated purposes are to improve the quality of health care, but whose necessary side effects are to raise the cost of health care.
Another government intervention with the free market is the subsidy. A subsidy makes the price appear smaller to the buyer than the actual transaction price. The graphical effect is to shift the demand curve up. Buyers will purchase at higher prices than they would have without the subsidy.

Figure 3.

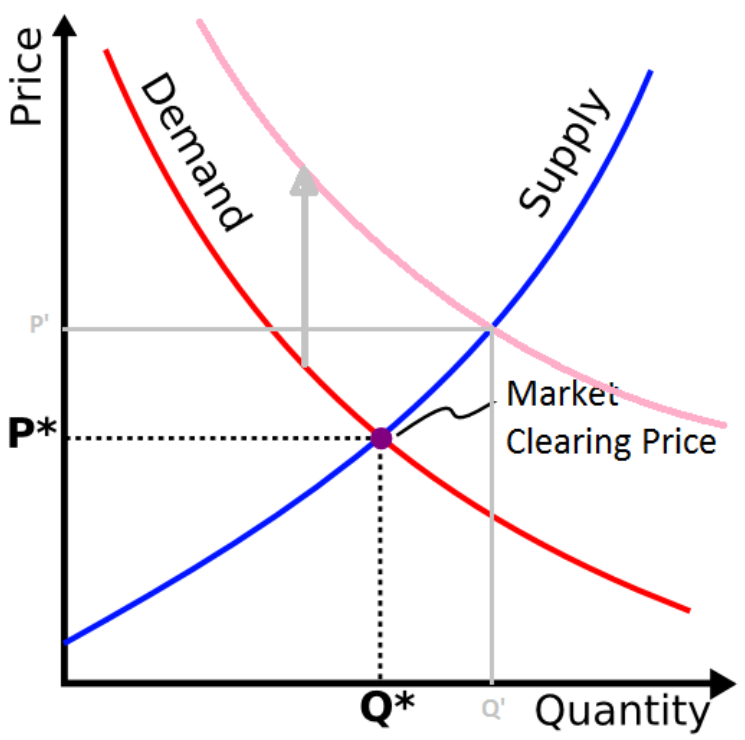

Just as with the regulation, there are two effects - on is intended and the other is unintended. The purpose of the subsidy is to increase the number of exchanges and the subsidy is successful in that regard. We see in Figure 3 that the new market clearing quantity ( $\left.Q^{\prime}\right)$ is greater than the unhampered market clearing quantity $\left(Q^{*}\right)$. Unfortunately, the unintended sided effect is an increase in market clearing price from $\mathrm{P}^{*}$ to the higher value $\mathrm{P}^{\prime}$. Contrary to popular belief, neither Medicare nor Medicaid is an insurance system. These government programs are large scale subsidies for the purchase of health care. The programs are successful at increasing the volume of health care provided, but they both increase the cost of health care by shifting the demand curve for health care.

As the combination of regulation and subsidy makes the cost of something, such as health care, unaffordable to nearly everyone, government pulls the price control out of its tool box of interventions. 
The effects of price controls are more complicated as they do not shift the supply or demand curves.

Figure 4.

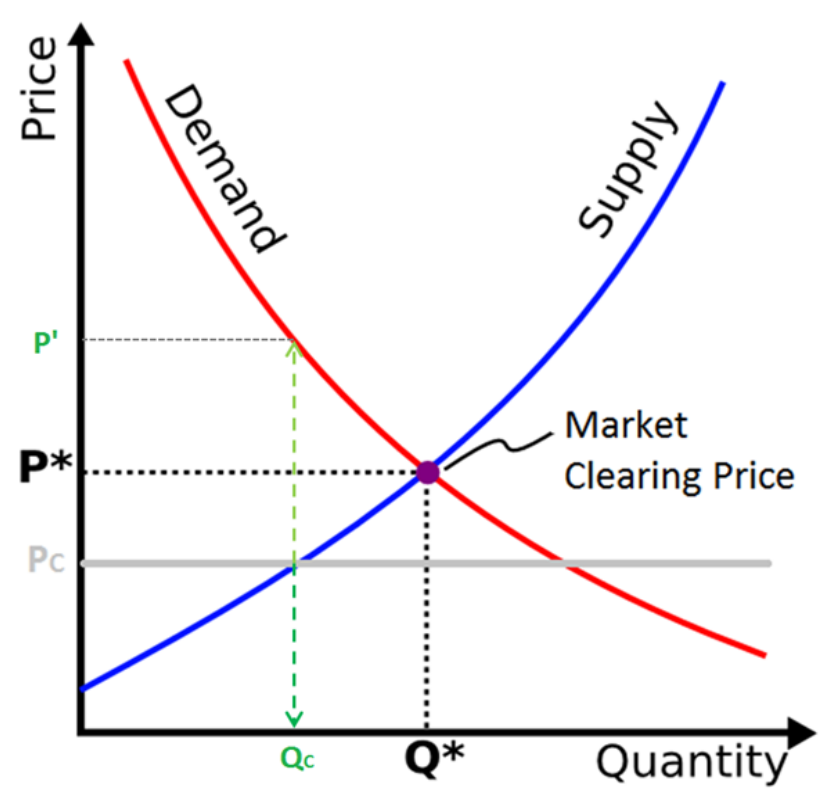

Figure 4 illustrates a price control (grey line at Price $=\mathrm{PC}$ ) below the market clearing price. At the price control of $\mathrm{PC}$, there are both unsatisfied sellers and unsatisfied buyers. Only QC sellers will still sell at the price control of PC (dark dashed green arrow). The difference between $Q^{*}$ and $Q C$ are unsatisfied sellers and unsatisfied buyers. The unsatisfied buyer at the margin is willing to pay price $\mathrm{P}^{\prime}$, which is even higher than the market clearing price $\mathrm{P}^{*}$, due to the lower quantity QC (light dashed green arrow). The unsatisfied sellers can take advantage of the price gap between P' and PC by bundling goods or services.

Bundling can take many forms. The seller could offer some worthless item for $\mathrm{P}^{\prime}$ and throw the price controlled item in for free. The service of free delivery could be offered. Combinations of goods whose value add up to P' can be offered to induce the purchase of the price controlled item.

Price controls on labor have had a major impact on the U.S. Health Care market. During World War II, the U.S. Government imposed wage and price controls. Employers bundled health insurance into the compensation package to induce workers to take jobs at the low wage control level. Employer based health insurance became the norm for the U.S. health care market.

Prior to Medicare, primary care physicians made house calls. The house call has essentially disappeared with Medicare due to low reimbursement for the patient visit. The new model is an assembly line office visit where expensive lab tests, imaging and diagnostic procedures are bundled in with the patient visit. It is very easy for physicians to bundle high cost items with price controlled services due to the large subsidies offered by Medicare.

The thoracentesis is illustrative of bundling to get around price controls. In 1989, when I left academia to enter private practice, I tried to offer thoracentesis in the office. I discovered that the reimbursement for a thoracentesis was less than the cost of the procedure tray. The hospital was happy to let me do thoracentesis in the Emergency Room, since the hospital could add a high priced ER charge to the bundle. As ER reimbursement declined, the hospital required an ultrasound for 'guidance' whether I needed it or not. Interventional radiologists decided to perform the thoracentesis for, essentially, free by adding a CT scan to the procedure. In 2014, it has become normal operating procedure to admit the patient to the hospital overnight, and add various imaging tests to the hospital charges. The total fee for a thoracentesis has gone from what should be less than $\$ 100$ to more than $\$ 1000$.

The irony of price controls is that buyers at the margin end up paying more than they would have without the price control. As health care became less and less affordable, higher and higher subsidies became necessary for the average person which led to even higher priced bundling. It is not at all uncommon for the total fee of a procedure that takes an hour or so to perform to be tens of thousands of dollars.

Health care is no longer affordable for the average person in the United States. The primary cause of this problem is government interference with the 
unhampered or free market. More interventions will only make the problem worse.

Author Affiliation: Dr. Berdine is a pulmonary physician in the Department of Internal Medicine, TTUHSC.

Received: $4 / 24 / 2014$

Accepted: 6/10/2014

Reviewers: Benjamin Powell PhD

Published electronically: 7/13/2014 